\title{
CORRIGENDUM
}

\section{Estimating energy expenditure in mice using an energy balance technique}

\author{
Y Ravussin, R Gutman, CA LeDuc and RL Leibel
}

International Journal of Obesity (2013) 37, 473; doi:10.1038/ijo.2012.147

Correction to: International Journal of Obesity (2013) 37, 399-403; doi:10.1038/ijo.2012.105; published online 3 July 2012

Since the online publication of this article it has been brought to our attention that two items in the manuscript need clarification or correction. These amendments do not change the inferences reached. We thank KD Hall $(\mathrm{NIH})$ for bringing these points to our attention.

The error has now been rectified and the corrected article appears in this issue. The html and online pdf versions have also been rectified and now carry the corrections.

The authors would like to apologise for this error

\section{CLARIFICATION}

Equation 2 posits:

$$
\mathrm{TEE}_{\mathrm{bal}}=\mathrm{MEI}+(\Delta \text { somatic fat energy }+\Delta \text { somatic fat-free energy })
$$

Assuming that changes $(\Delta)$ in somatic chemical energy content are calculated as initial minus final during the period of $\mathrm{TEE}_{\mathrm{bal}}$ (as we did), this equation is correct.

However, as Equation 2 is actually a restatement of Equation 1:

\section{$\Delta$ somatic energy content $=$ total energy intake} - total energy expenditure

for consistency and clarity, Equation 2 should read MEI minus changes in somatic energy content:

$\mathrm{TEE}_{\text {bal }}=\mathrm{MEI}-(\Delta$ somatic fat energy $+\Delta$ somatic fat-free energy $)$

with changes in body composition calculated as final - initial (FM or FFM) of the period of $\mathrm{TEE}_{\mathrm{bal}}$. Both formulations of course give the same result, but the Equation 2 revised is more intuitive and is consistent with the form of Equation 1 (also see ${ }^{1}$ ).

\section{CORRECTION}

In the paragraph entitled 'Estimates of TEE using energy balance $\left(\mathrm{TEE}_{\mathrm{bal}}\right)$ ', before Equation 2, we state that 'The energy cost of depositing dietary calories as somatic tissue is greater than that released by their oxidation. We assigned $13.2 \mathrm{kcal}$ for each gram of fat mass (FM) gained, and $9.0 \mathrm{kcal}$ for each gram of FM lost; $2.2 \mathrm{kcal}$ for each gram of fat-free mass (FFM) gained and $1.0 \mathrm{kcal}$ for each gram lost.' This differential assignment of energy costs of tissue anabolism/catabolism-and the adjustments in $\mathbf{T E E}_{\text {bal }}$ deriving from their application - are not necessary for the calculation of $\mathbf{T E E}_{\mathbf{b a l}}$. As $\mathrm{TEE}_{\mathrm{bal}}$ is calculated directly from MEl and changes in somatic mass and composition, energy costs related to tissue deposition or mobilization are inherently accounted for by these independent variables. Thus, in the present case, fixed, equal caloric equivalents of FM and FFM can be assigned to gains or losses of somatic mass. ${ }^{2}$

Assigning caloric equivalents for $F M=9.4 \mathrm{kcalg}^{-1}$ and $\mathrm{FFM}=1.0 \mathrm{kcal} \mathrm{g}^{-1}$ gained or lost, ${ }^{3,4}$ we recalculated $\mathrm{TEE}_{\text {bal }}$ using Equation 2 revised. As expected, this simplified estimate of $\mathbf{T E E}_{\text {bal }}$ has minimal effects in the current study owing to the relatively small change in body mass among the different groups: for example, mean differences (between $\mathrm{TEE}_{\mathrm{bal}}$ and $\mathrm{TEE}_{\mathrm{IC}}$ ) for the two techniques (revised Figure 1d) were only $2.3 \%$ higher in DIO$\mathrm{AL}, 1.1 \%$ higher in DIO-WR, $1.0 \%$ higher in CON-AL and $0.9 \%$ higher in CON-WR for the recalculated versus original values (see revised Figure 1d). Likewise, the correlations of TEE by balance and calorimetry were essentially unaffected: $R^{2}=0.8754$ in original calculation (Figure $1 \mathrm{~b}$ ) and $R^{2}=0.8686$ in the revised calculation (revised Figure 1b).

\section{REFERENCES}

1 Guo J, Jou W, Gavrilova O, Hall KD. Persistent diet-induced obesity in male C57BL/6 mice resulting from temporary obesigenic diets. PLoS One 2009; 4: e5370.

2 Hall KD. Mathematical modelling of energy expenditure during tissue deposition. Br J Nutr 2010; 104: 4-7.

3 Pullar JD, Webster AJ. The energy cost of fat and protein deposition in the rat. $\mathrm{Br} J$ Nutr 1977; 37: 355-363.

4 Schulz LO, Alger S, Harper I, Wilmore JH, Ravussin E. Energy expenditure of elite female runners measured by respiratory chamber and doubly labeled water. J Appl Physiol 1992; 72: 23-28. 